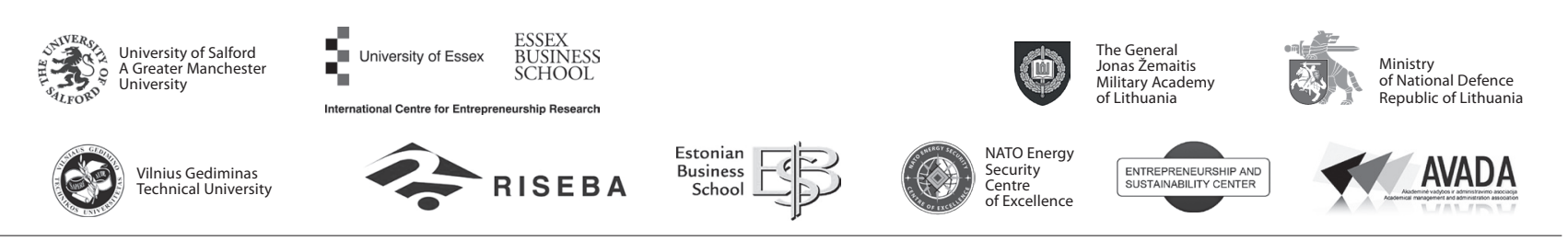

JOURNAL OF SECURITY AND SUSTAINABILITY ISSUES

ISSN 2029-7017 print/ISSN 2029-7025 online

2018 September Volume 8 Number 1

https://doi.org/10.9770/jssi.2018.8.1(2)

\title{
SUSTAINABILITY ISSUES IN THE MILITARY: GENESIS AND PROSPECTS
}

\author{
Rasa Smaliukiene \\ General Jonas Žemaitis Military Academy of Lithuania \\ Šilo Str. 5A, LT-10322 Vilnius, Lithuania, \\ E-mail: rasa.smaliukiene@lka.l
}

Received 20 January 2018; accepted 20 June 2018

\begin{abstract}
Despite the rising recognition and a growing body of literature on sustainability issues in the military, no comprehensive and systematic review on the topic has been published yet. Accordingly, the aim of this paper was to deconstruct the topic of sustainability in the military context by exploring its genesis, state-of-the-art knowledge and future prospects. Furthermore, the study addressed the question of practical importance about where sustainability in the military is ad hoc or institutionalized into management processes and procedures of organizations. The paper relied on the systematic literature review and used a bibliometric data analysis: citation network and keyword network analysis techniques were employed to select, analyse and interpret the genesis and prospects in the field.

The data suggest there are three dominating research streams in the field: (1) environmentally sustainable solutions, (2) economic (un) sustainability of militarization and (3) social cohesion. The recent research on sustainability in the military marks a new trend where all three fields of sustainability are being integrated. It is also apparent form the analysis that a small but significant share of publications indicates institutionalization of sustainability in the military practice. This is particularly evident in relation to environmental issues.
\end{abstract}

Keywords: sustainability; military; institutionalization; management; systematic review

Reference to this paper should be made as follows: Smaliukiene, R. 2018. Sustainability issues in the military: genesis and prospects, Journal of Security and Sustainability Issues 8(1): 19-32. https://doi.org/10.9770/jssi.2018.8.1(2)

JEL Classifications: 032

\section{Introduction}

Sustainability is becoming a central discussion issue around the future planning of military training, operations and installations. An increasing demand for energy and public pressure to reduce emissions as well as improve recyclability raises a question of how to comply with sustainability requirements while enhancing military capabilities. This issue emphasises the need to understand the genesis of sustainability and at the same time to look at the prospects of its development.

Whenever sustainability issues in the military are discussed, in the first instance, sustainable energy consumption is emphasised. A long-term strategic view on sustainable energy consumption is becoming an integral part of military planning as energy initiatives are binned to the mission capabilities. In parallel to the growing comprehension on sustainable energy consumption, other environmental issues related to military activities are increasingly raising an interest of researchers and practitioners. The data provide evidence that the armed forces are one of the largest polluter on earth (Jorgenson and Clark 2016). Soil contamination of the military bases, caused by military pipeline leaks, transport accidents, as well as the usage of chemical warfare agents raise concerns, especially when military ranges are returned to non-military entities (Pidlisnyuk et al. 2016; Jugnia et al. 2018). 
Moreover, the military has an economic and social effect on local communities as military bases and their logistic network catalyse regional economic and social development. As for the military's role in counter-insurgency operations, it is directly related to job creation (Greenburg 2017). Besides a positive economic effect, the military makes a less favourable impact on social sustainability. Bases and training areas reshape urban infrastructure and as documented in the study (Havlíček et al. 2018), large military bases in the country affect the road network and in some cases cause physical as well as social and economic isolation of communities in remote areas.

Despite the rising recognition and growing body of literature on sustainability issues in the military, no comprehensive and systematic review of sustainability in the military has been published. Accordingly, the aim of this paper was to deconstruct the topic of sustainability in this context by exploring the genesis, state-of-the-art knowledge and future prospects. Furthermore, the study addressed the question of practical importance about where sustainability in the military is ad hoc or institutional (integrated into management processes and procedures of organizations).

The paper is divided into several parts. It starts with research methodology where the systematic literature review is explained as the main method of the study. It is illustrated with a research flow diagram and explicated using data statistics. The second part presents the bibliometric analysis and illustrates an increasing interest in the topic. The third and fourth parts of the paper present results from the bibliographical and content network analyses. Using these two different research methods citation and keyword networks are created. They represent the genesis of sustainability in the military research as well as a new trend in the field; moreover, results identify the fields where sustainability solutions are institutionalized at the organizational level in the military. The paper concludes debating possible future directions of sustainability in the military.

\section{Research methodology and data statistics}

A systematic literature analysis was chosen as a research method for this study as it uses a well-defined methodology that ensures unbiased evidence through collecting, analysing and interpreting secondary data (Budgen and Brereton 2006). It also allows focusing on concepts, i.e. the study becomes concept-centric as opposed to a widespread and frequently criticized author-centric approach (Webster and Watson 2002).

Systematic literature analysis is used in socioeconomic sciences and humanities, environment, ICT, health as well as other research fields. Regardless of the field, this method is characterized by several steps (Budgen and Brereton 2006; Ritz et al. 2016): (1) the analysis begins with a research question and is followed by a (2) review protocol that defines a strategy for data collection, (3) the analysis provides clear inclusion and exclusion criteria and, finally, (4) it is consistently described to allow replication of the results.

Research Questions. The research questions which should be answered in this analysis relate to the aim and are as follows: (1) To what extent is scientific literature interested in sustainability in the military? (2) Which field of study is most analysed in terms of sustainability in the military? (3) How are research fields connected and how do they change over time? (4) Does sustainability in the military form a comprehensive field of knowledge? (5) What are the fields where sustainability is integrated into the organizational management, i.e. sustainability is institutionalized?

Review Protocol. A review protocol (Fig.1) defines the steps that need to be taken to answer the research questions. In order to achieve reliable results it is important to select appropriate scientific databases for data extraction as well as have a search strategy that describes the requirements for data inclusion and exclusion. 


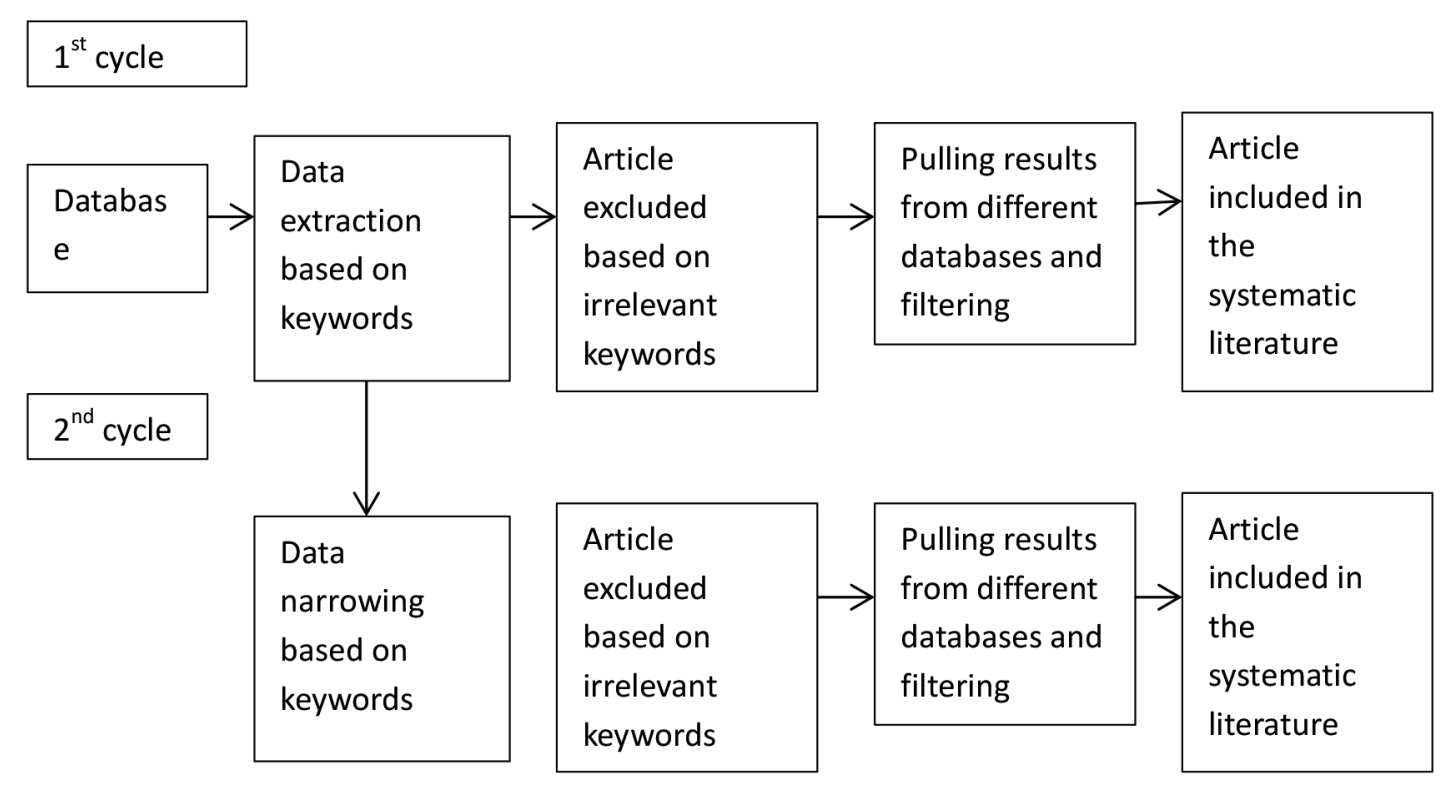

Fig. 1. Review Protocol for Data Collection

Two main scientific databases were used for the study: Scopus and Web of Science - Clarivate Analytics (VoS). We performed a 2-cycle search in both databases using a review protocol. In the $1^{\text {st }}$ cycle we looked for articles on sustainability issues that were related to the military at large. In the $2^{\text {nd }}$ cycle, we focused only on those articles that were directly linked to the institutionalization of sustainability. The time frame was from 1978 to 2018 (41 years), but the first paper where the management perspective was introduced dates back to 2004 (Hoskin 2004).

Data inclusion and exclusion. Data collection in the $1^{\text {st }}$ cycle was performed using a combination of keywords military or army and synonyms of the word sustainability. Thesaurus dictionaries such as www.collinsdictionary.com, www.powerthesaurus.org and www.thesaurus.com revealed the existence of synonyms of the word sustainability, namely - durability, renewability, coherence, coherency, cohesion, cohesiveness and endurance. We used the beginnings of the word sustainability and its synonyms in our search accordingly: sustain*, durab*, renewab*, social cohe*. Additionally, we excluded three most recurrent irrelevant keywords as species, clinic and habitat. 1,677 papers were found in total (in VoS N909 and in Scopus N768). The total number of papers decreased to 1,056 after deleting duplicates and reviewing them manually (Table 1). In order to concentrate on institutionalization of sustainability, we filtered all search results and focused on the field of management (as a search keyword) during the $2^{\text {nd }}$ cycle of data extraction. As a result, the total number of papers decreased to 228 (Table 1). This extraction strategy allowed us to focus on general trends during the first stage and emphasise sustainability in the military management during the next stage.

To further analyse the data, the search results of Scopus and VoS were combined using CRExplorer. Bibliographical data analysis was performed using HistCite Software LLC and VosViewer 2018 was used for content analysis. In both cases we employed network analysis where authors of the publications and keywords symbolized as nodes. Each link between the nodes was weighed as they represented the number of co-occurrences in different articles. Statistical as well as visual analysis is provided below. Data cleaning for content analysis was performed using a thesaurus file. Thesaurus file was based on JEL Classification System 2016 and IEEE Thesaurus Version 1.02017. 
Table 1. Search Results for Selected Keywords

\begin{tabular}{|c|c|c|c|}
\hline & VoS & Scopus & $\begin{array}{c}\text { Total } \\
\text { (after deleting duplicates) }\end{array}$ \\
\hline \multicolumn{4}{|c|}{ A. For selected keywords in all subject areas } \\
\hline Records & 909 & 768 & 1,06 \\
\hline Authors & & & 2,59 \\
\hline Journals & & & 833 \\
\hline Cited References & & & 3,69 \\
\hline \multicolumn{4}{|c|}{ B. For selected keywords in the subject area of management } \\
\hline Records & 153 & 214 & 228 \\
\hline Authors & & & 606 \\
\hline Journals & & & 201 \\
\hline Cited References & & & 7,44 \\
\hline
\end{tabular}

\section{General trends in the field}

To illustrate general trends and the increasing interest in sustainability in the military we produced a graph showing the numbers of publications by year. Although the number of publications is constantly growing, the dynamics are fluctuating (fig.2). The period of 2003-2009 is marked by a constant growth of the research in the field. Taking into consideration all publications in the field, the first significant increase in the number of publications was seen in 2009 when the number of publications doubled. It was influenced by three main publications that have a high global index and are written by the same authors (Banks and Stytz 2003). Further analysis of the trends highlights the year 2012 where publications in the field of human resource management had the highest global ranking (Bedwell et al. 2012). Looking at the numbers of publications by year, it is evident that the interest in the field has increased dramatically over the last few years: the highest number was reached in the period of 2015-2017, when the annual number of publications exceeded 100 papers. The publications in the discipline of management remain on a more constant level with a more remarkable increase in 2014 when Green Defence Framework (2014) as a policy paper of NATO was published (Fig. 2).

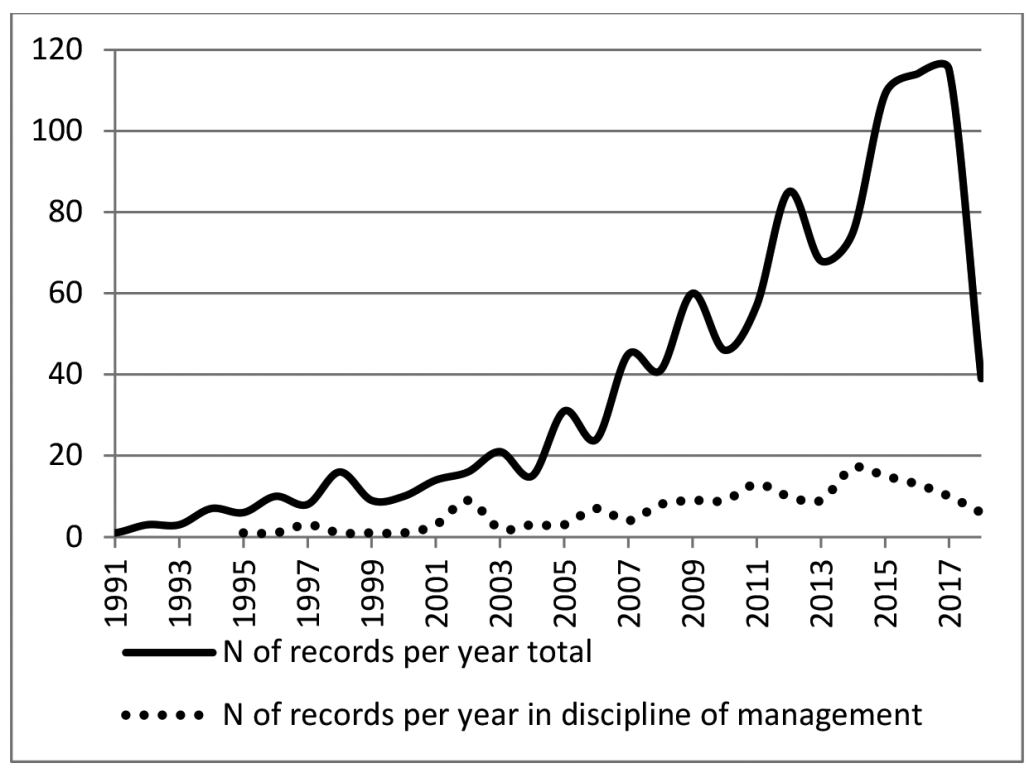

Fig. 2. Publishing Trends in the Field of Sustainability Issues in the Field of Military Studies in General and in the Discipline of Management (up to June, 2018)

The authors of publications represent 86 countries and demonstrate a cross-national interest in the topic. It is also worth mentioning that authors from English-speaking countries predominate and their publications amount to more than $70 \%$ of all publications (Tab. 2). 
Table 2. Affiliation Statistics

\begin{tabular}{|l|c|c|c|}
\hline \multicolumn{1}{|c|}{ Country } & Records & Local Citation Score & Global Citation Score \\
\hline USA & 405 & 29.3 & 90 \\
\hline UK & 106 & 10 & 22 \\
\hline Canada & 47 & 4.5 & 11 \\
\hline Australia & 36 & 3.4 & 2 \\
\hline Germany & 35 & 3.3 & 9 \\
\hline
\end{tabular}

To measure the growing interest in the field, we also analysed the trends in citation scoring of the respective publications. The period of 2007-2012 was notable for high-ranked publications (Fig.3). While analysing publications in the discipline of management, the year 2012 was noteworthy.

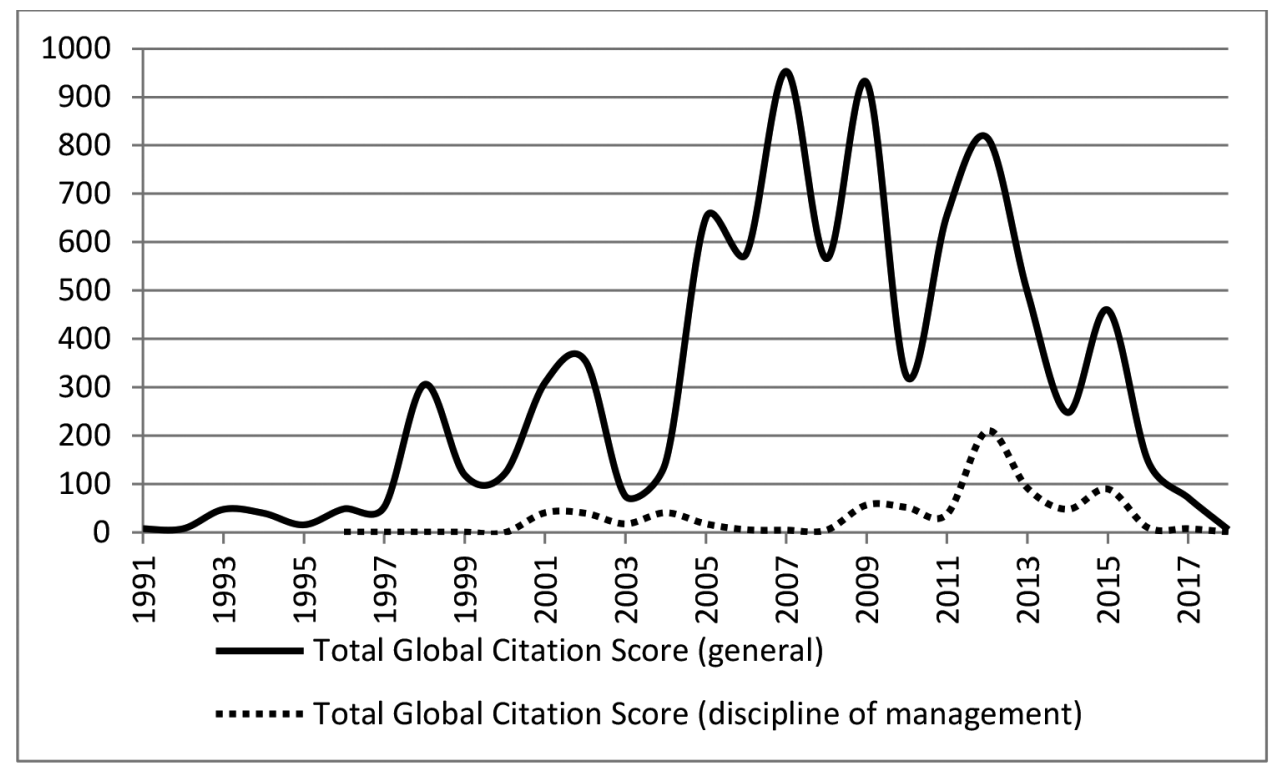

Fig. 3. Trends in Total Global Citation Scoring of the Publications

As the field of sustainability is an interdisciplinary one, there is no dominating publisher for the papers we analysed. The journal Armed Forces \& Society has 18 publications on sustainability issues, and thereby it is the main publisher in the field with the highest citation score (Tab.3). Publishers of publications on management are interdisciplinary scientific journals.

Table 3. Top 3 Publishers in the Field

\begin{tabular}{|c|l|c|c|} 
& \multicolumn{1}{|c|}{ Journal } & Records & $\begin{array}{c}\text { Citation } \\
\text { Score }\end{array}$ \\
\hline & A. In all subject areas & \\
\hline 1 & Armed Forces \& Society & 18 & 40 \\
\hline 2 & Journal of Peace Research & 11 & 1 \\
\hline 3 & Military Psychology & 9 & 23 \\
\hline & B. In a subject area of management & & 31 \\
\hline 1 & Picmet: Portland International Center for Management of Engineering and Technology & 3 \\
\hline 2 & Presence-Teleoperators and Virtual Environments & 3 \\
\hline 3 & Journal of Security and Sustainability Issues & 3 & 3 \\
\hline
\end{tabular}




\section{Citation network analysis and leading theories in the field}

To further analyse the genesis of knowledge on sustainability in the military, we employed the historiographical compilation and identified the most influential scientist in the field. At the same time the citation network using historiographs allowed us to answer one of the most challenging questions - if sustainability in the military can be considered as a comprehensive field of knowledge.

We selected 15 most cited papers and created a historiograph of sustainability in the military research literature (Fig.4). The historiograph represents the total number of publications per year and interlinkages of most cited papers. 11 papers were merged into one cluster which means that articles starting with the publication by Oliver et al. (1999) and ending with the one by McLauchlin (2015) formed a solid body of knowledge. Four publications were left out from this core cluster; by analysing in depth they were leading in separate thematic areas (Fig.5).

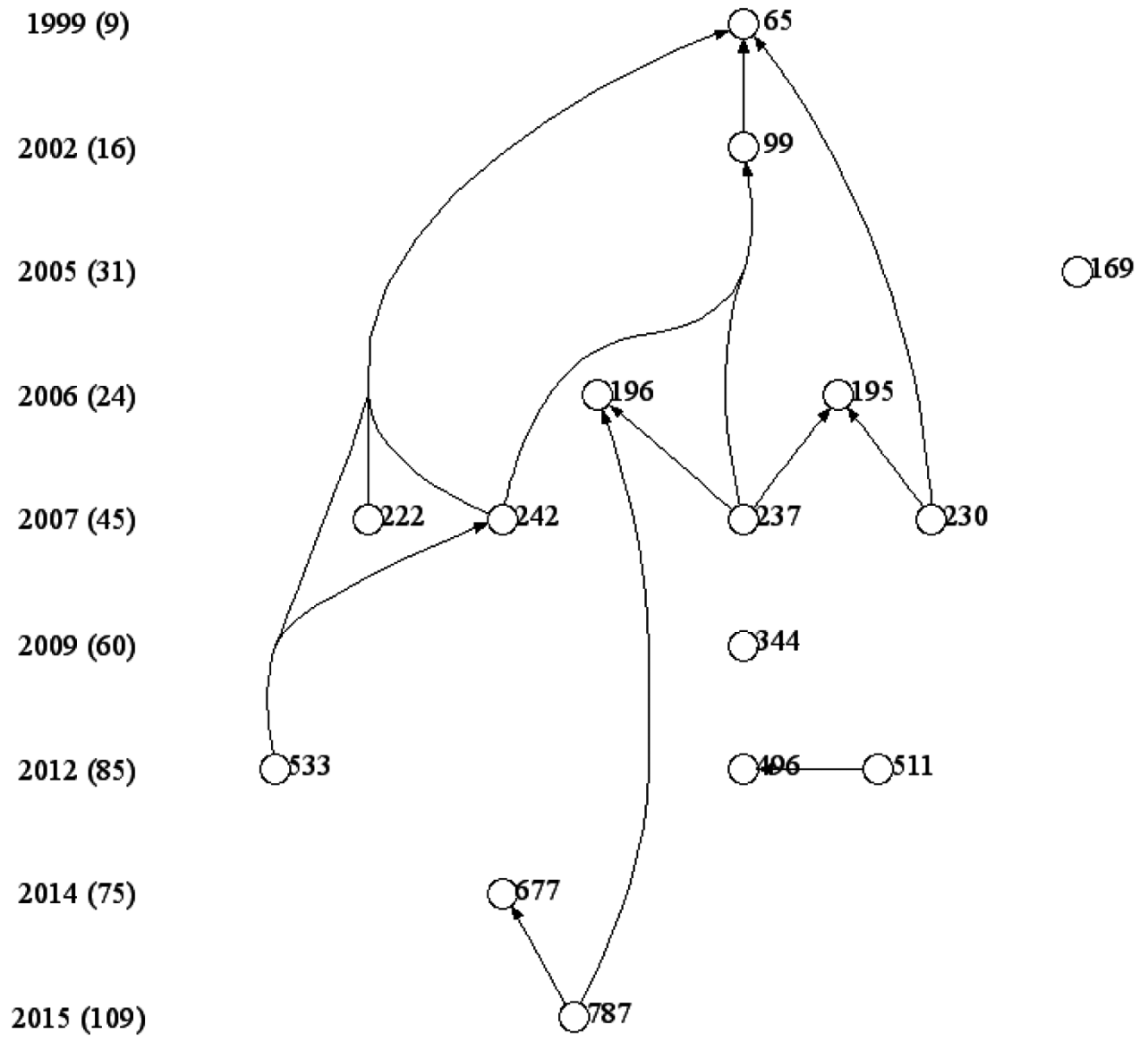

Fig. 4. A Historiograph of Leading Publications on Sustainability in the Military ${ }^{1}$ 
Table 4. Leading Publications in the Field by Global Citation Score

\begin{tabular}{|c|l|c|}
\hline ID & \multicolumn{1}{|c|}{$\begin{array}{c}\text { Leading publications } \\
\text { Global citation } \\
\text { score }\end{array}$} \\
\hline 242 & Brailey K, 2007, J TRAUMA STRESS, V20, P495 & 94 \\
\hline 344 & Jorgenson AK, 2009, SOC PROBL, V56, P621 & 77 \\
\hline 65 & Oliver LW, 1999, MIL PSYCHOL, V11, P57 & 72 \\
\hline 230 & Siebold GL, 2007, ARMED FORCES SOC, V33, P286 & 66 \\
\hline 195 & King A, 2006, ARMED FORCES SOC, V32, P493 & 57 \\
\hline 99 & Griffith J, 2002, MIL PSYCHOL, V14, P217 & 47 \\
\hline 196 & MacCoun RJ, 2006, ARMED FORCES SOC, V32, P646 & 37 \\
\hline 496 & Sabatini JJ, 2012, CHEM-EUR J, V18, P628 & 27 \\
\hline 511 & Sabatini JJ, 2012, CHEM-ASIAN J, V7, P1657 & 23 \\
\hline 222 & Ahronson A, 2007, MIL PSYCHOL, V19, P9 & 19 \\
\hline 237 & King A, 2007, ARMED FORCES SOC, V33, P638 & 16 \\
\hline 533 & Mitchell MM, 2012, SUICIDE LIFE-THREAT, V42, P486 & 15 \\
\hline 677 & McLauchlin T, 2014, J CONFLICT RESOLUT, V58, P1419 & 10 \\
\hline 787 & McLauchlin T, 2015, INT STUD QUART, V59, P669 & 9 \\
\hline 169 & Rao NH, 2005, CURR SCI INDIA, V88, P1753 & 3 \\
\hline
\end{tabular}

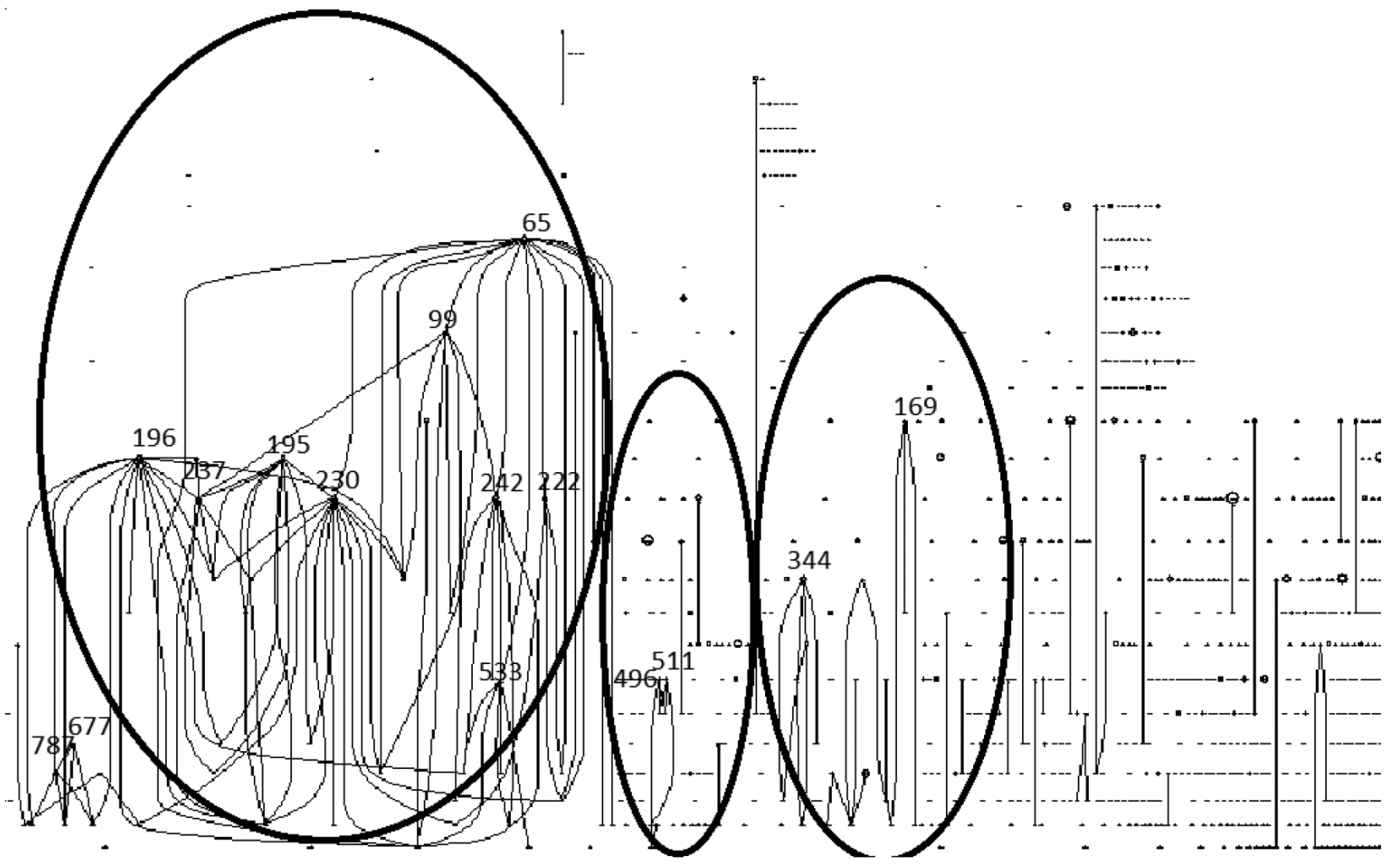

Fig. 5. Historiographical Clustering of all Publications on Sustainability in the Military2

Historiographical clustering revealed three groups of publications in the area of sustainable development (Fig.5). The largest cluster, which is highly homogeneous in terms of the scope, consists of publications dealing with social sustainability that focuses on social cohesion. The other two clusters are smaller and more evaporated: environmental issues are analysed from the perspective of life sciences while economic sustainability in the military is largely covered by research in political economy. 
It is worth noting that only a small cluster of publications represents a "classical" approach to sustainability and directly addresses the environmental impact of military activities. The two leading publications in this cluster are led by the same authors - Sabatini et al. (2012a) (2012b) (Fig.5 No 496 and No 511). They provide actual and environmentally conscious solutions as how to reduce the impact of chemicals used in the military lights (pyrotechnics). The majority of publications in this cluster focus on issues related to environmental pollution as the military is the biggest producer of greenhouse gas emissions. Based on the study by Bildirici (2018), up to $51 \%$ of $\mathrm{CO} 2$ emissions is explained by militarization in some largest countries. Accordingly, authors propose engineering and management solutions that would optimize energy management systems and reduce fuel consumption (Anglani et al. 2017). A range of research programmes is initiated to evaluate field conditions and technologies that may reduce contamination of soils and contribute to sustainable land use (Wang et al. 2013; Fayiga and Saha 2016; Jugnia et al. 2018).

Sustainability in the military context is not only an issue, but also a strong stimulus for initiatives that foster efficiency. Military bases are perceived as small cities where sustainable planning approach is crucial (Hubbard et al. 2017) and a variety of managerial measures should be applied. Environmental management systems (EMS), life-cycle assessment (LCA), key performance indicators (KPIs), behavioral patterns of energy consumption, and other methods and tools are validated on the military bases and during their activities (Oglanis, A., Loizidou M. 2017; Tvaronaviciene et al. 2018). Researchers (Procter et al. 2016; Allen and Deal 2017) investigated sustainability strategies and simulated urban metabolism by incorporating multiple areas related to sustainability issues in the military such as energy, water, and waste. Rao (2005) and other scientists employed the paradigm of environmental management and provided solutions for integrating sustainability issues into military missions. Wu et al. (2010) analysed how ISO 14001 Environmental Management System operates with respect to military activities and outlined a legislative framework and environmental policies that included measures for risk reduction, environmental awareness training as well as other management solutions. The number of publications, including their interdisciplinary nature, has increased over the recent years after the NATO's Green Defence Framework (2014) was adopted. They reflect the requirements of the framework and provide solutions for using less resources and enhancing sustainability. To conclude, the publications in the cluster transfer knowledge form fundamental research to military practice.

Economic pillar of sustainability in the military research was led by Jorgenson and Clark (2009) (Fig. 5, No 344) who employed multiple theories within a political economy framework to analyse the interconnection between military expenditures and ecological footprint of nations. These authors continued their investigation for more than five years and concluded that even though military spending remains substantive, the complexity of military-industrial interrelationship has diminished, i.e. military's positive impact on the economic development has decreased substantially (Jorgenson and Clark 2016). In contrary, hi-tech weaponry is turning the military into a capital- and knowledge-intensive industry. Contemporary military is no longer an employer for the uneducated and unskilled youth, thus causing significant concerns for those individuals and the society at large (Kentor et al. 2012). In addition, military expenditure exacerbates income inequality and increases the unemployment rate in low and middle income countries (Tang et al. 2009). Recent research provides evidence on unsustainable social impact of military expenditures: hi-tech military expenditures have "a significant negative impact on the short- and long-term health outcomes of children and adults, in both developed and less-developed countries" (Kentor and Jorgenson 2017) which must be considered in terms of sustainable development.

The analysis of military redeployment for the missions abroad also showed negative economic consequences caused by unsustainable urban development. Kim (2017) analysed the third biggest US military base overseas and concluded that military base departures from South Korea produced a long-lasting negative effect as most sites remained empty and heavily contaminated, plagued by redevelopment issues. Base closures are perceived as "local economic shocks that can potentially devastate local economies, particularly in communities with a high concentration of military activity" (Lee 2016).

The social aspect of sustainability in the military research (the largest cluster) is dominated by health researchers, psychologist and sociologists. Researchers analyse how military operations affect human physical and 
mental health and what the cost of the traumatic war experience is for the military and the society at large. The dominant topic of research is social cohesion. The publication by Oliver et al.(1999) was the first in the field of medicine that investigated group cohesion in military units. Brailey et al. (2007) and Siebold (2007) followed this with their own publication where they empirically validated the effect of unit cohesion on human health. As for military psychologists, they confirmed the effect of cohesion on individual and group combat readiness (Griffith 2002) and motivation in combat (MacCoun et al. 2006). Research in psychology and medicine connect for more in-depth results. Results showed that social cohesion makes a crucial impact not only on human health, but also on human life: as it was confirmed in the study by Mitchell et al. (2012), combat exposure is a significant risk factor for suicide-related ideas, while unit cohesion provides significant protection against this, thus policy recommendations were provided that stressed institutional measures to strengthen unit cohesion. Social values of sustainability represent people-oriented approach and lead research on human health and capability (Smaliukienè et al. 2011; Kaikkonen and Laukkala 2016) as well as on group cohesion and resilience of social structures (Charbonneau and Wood 2018).

Research on social sustainability in the military takes a unique paradigm and concentrates more on internal processes. In this way, social sustainability is about identifying and managing an impact on the personnel and on local communities which integrate military families and veterans. Social scientists analyse the same topic and present an innovative point of view on the phenomenon of cohesion that now interests non-military researchers. An interesting idea was presented by MacCoun et al. (2006) who divided cohesion in the military into social and task cohesion. Since then, the dual concept of cohesion has been widely used in research where social cohesion is seen as the strength of interpersonal bonds among unit's members and task cohesion is defined as a shared commitment to the unit's mission. It is proved that task-related cohesion is linked to satisfaction with work while social cohesion is inevitably associated with psychological distress and related to health issues (Ahronson and Cameron 2007). Research reveals that social cohesion and task cohesion in the military are two separate phenomena. This idea is transferred to non-military research and, as pointed out by Kirton and Maclaren (2018), the link between the performance in sustainable development and task cohesion as well as social cohesion is widely supported by literature.

Social sustainability in the military context is mainly perceived and analysed as a phenomenon of cohesion which, in turn, is understood as a positive incentive. Still, when the paradigm and methodology of other sciences are used, other insights are obtained. For instance, McLauchlin $(2014 ; 2015)$ analysed cohesion of armed groups and concluded that it depends not only on positive incentives, but also on control. His study is a great example of how expanding the scope of the research presents new insights. However, this interdisciplinary approach does not fall into the middle of the research cluster and remains at its edge (see 677 and 787 in Fig. 4).

The citation network analysis revealed that research on sustainability in the military is mainly carried out in the disciplines of medicine, psychology and sociology. This human-centric approach towards sustainability is disconnected with other disciplines. Meanwhile, environment- and economic-centred research papers create only small clusters in a large body of knowledge on sustainability in the military.

\section{Thematic network analysis}

We used keyword analysis to deliver the thematic network which provided a comprehensive understanding of how research areas are connected and how they change over time. Our findings using this analysis supported the results from the citation network analysis: keywords organized themselves into three clusters; however, the structure and size of the clusters were different. The biggest cluster (fig. 6) tackles sustainability directly and is connected with keywords used in political sciences: war, security, politics, terrorism, democracy, etc. Keyword sustainability has high value measured by time of occurrence whereas keywords as conflict and war have high centrality values and are connected to form one large network. The cluster is enhanced with crossdisciplinary perspective in a rather surprising way: keywords human resource management and personnel training appear to be connected with politics and identity or democracy and conflict instead of organization and management. 
The second cluster (fig. 6) has no clearly explicit centre; nevertheless, it integrates the keywords from a wide range of disciplines: social sciences (keywords: organization and management, strategies) are interconnected with engineering (keywords: software engineering, energy) using cross-disciplinary keywords such as model, system, integration. The cluster represents thematic interconnections among articles on environmental sustainability where energy (renewable energy) is a new flagship. This cluster is explained by the changing nature of warfare and technological advancements of the military where dependency on energy plays a vital role.

The third cluster (fig. 6) is dominated by military organization and gravitates around cohesion. As we already discussed when presenting the citation network analysis, cohesion represents social and human aspect of sustainability in the military research. Accordingly, the cluster consists of health related keywords such as mental health, stress as well as the ones related to social transactions - social support, leadership. Military in terms of sustainable development is seen not only as an actor in a macro- environment, but also as a stand-alone microsystem where internal processes need coherent approach.

Thematic network analysis disclosed the fields where sustainability in the military is institutionalized and management processes and procedures are proposed or established. As for the management discipline, the network presented an unexpected distribution of keywords. It can be seen that the keywords used in this discipline are scattered and non-related. For example, human resource management is in the cluster dominated by keywords of political sciences, and leadership is closer to the keywords of health sciences than to organization and management. Therefore, it can be concluded that when dealing with sustainability issues in the military management is used as a support methodology and not as a separate discipline. At the same time an intersection of the keywords of the management discipline discloses that sustainability is already institutionalized in the military organizations.

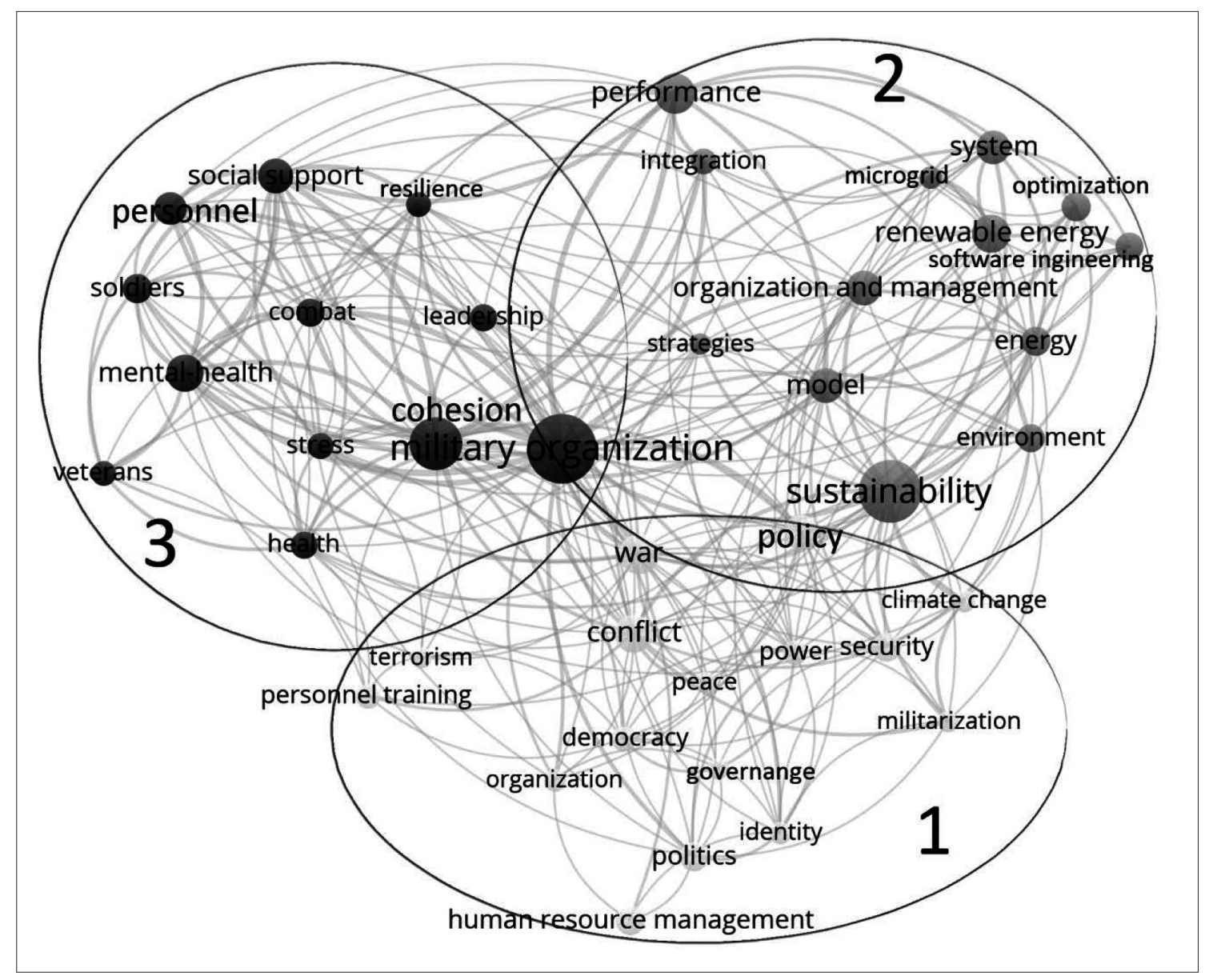

Fig. 6. Keywords Clustered by Co-occurrence of Terms in Publications 
Through the comparative analysis of the network built over time we were able to detect some interesting patterns. Taking into account that the topic of sustainability issue in the military research has been evolving only since 2009, there are three emerging research areas worth mentioning. These areas are marked with the keywords from all three clusters. Health, management, renewable energy and militarization are the main keywords indicating new or emerging topics in the field (fig. 7). The newest trends indicate that sustainability is becoming a central concept while ancillary terms such as cohesion are disappearing from the research field. The publication by Hardcastle et al. $(2015,2015)$ illustrated this new pattern. The authors analysed medical treatment facilities in terms of safety and energy sustainability requirements. Similar evidence comes from the field of social sciences where the dominating keyword militarization is directly (usually in the negative or diverse context) linked to sustainability. As illustrated by Marzec (2015), Dunlap (2016, 2016) or Jorgenson and Clark (2016), military as an institution is important when considering any nation's sustainability and especially environmental issues. Authors using militarization and sustainability as keywords in their articles offer a comprehensive analysis of social drivers of sustainable development and at the same time give clear evidence that the topic of sustainability is becoming an interdisciplinary one. The centrality of sustainability as a node and its direct linkages with the newest keywords identify the interconnection of the topics in the field as well as indicate that in the future the body of knowledge on sustainability in the military may become more coherent.

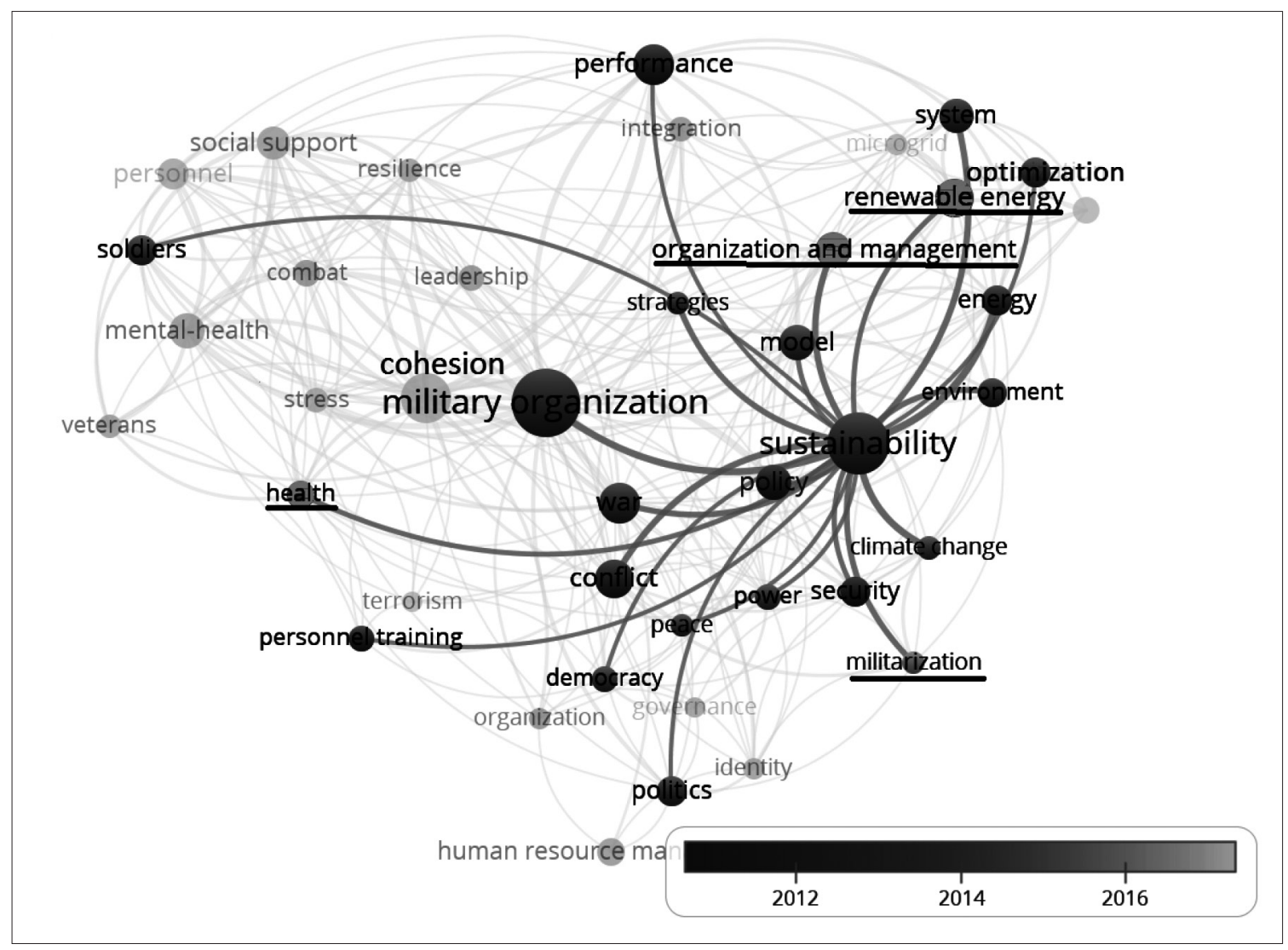

Fig. 7. Keywords Clustered by Co-occurrence Over Time Periods: Network Centered Around Keyword 'Sustainability'

\section{Conclusions}

This study identifies a notable development of literature on sustainability issues in the military and displays an imbalanced structure of different research approaches. Human-centric approach towards sustainability is dominating compared to environmental and economic aspects. However, recent publications mark a new trend where all three aspects of sustainability are being integrated.

Our findings show that sustainability in the military is becoming an important paradigm in which a common body of knowledge as well as institutionalized practices are being developed. There are three dominating re- 
search streams in the field: (1) social cohesion, (2) environmentally sustainable solutions and (3) economic (un) sustainability of militarization. The first field is mainly represented by research in the field of health and social sciences. Social sustainability in the military context is perceived and analysed as a phenomenon of cohesion. Social cohesion is proved to be a strong 'remedy' for physical and mental health for intra-organizational communities. The topic takes a unique paradigm and concentrates on internal processes, at the same time it provides an innovative point of view on the phenomenon of cohesion that now has been fully analysed by non-military researchers. The research shows that social cohesion is most fully developed topic of sustainability in the military, yet it loses its relevance as health issues are becoming directly related to the broad concept of sustainability.

Environmentally sustainable solutions mark the second field of research on sustainability in the military. According to the number of publication, it is the least investigated topic. Nevertheless, research results on environmental sustainability in the military provide solutions for practical application. Military, as a big consumer of energy and a large polluter, demands diverse solutions as to how efficiency in resource consumption should be increased without sacrificing mission effectiveness. Accordingly, environmentally sustainable solutions found in life sciences and engineering are institutionalized into management systems in the military. In this area, a great integrity of science and practice is developing.

The third field of research focuses on economic (un)sustainability of militarization and is dominated by economic policy researchers. The research results provide evidence of the changing role of the military in terms of national economy. As hi-tech weaponry is making the military a capital- and knowledge-intensive industry, it is no longer an employer for the uneducated and unskilled youth, thus causing significant concerns for those individuals and the society at large. The research in the field of economic sustainability indicates that military expenditure exacerbates income inequality and calls for changes in the policy. The predominance of the paradigm of economic policy-making has created an isolated field of research on sustainability in the military. The newest articles in the field, however, already provide solutions that have an interdisciplinary perspective.

A small but significant share of publications indicates institutionalization of sustainability in the military procedures and operations. This is particularly evident in relation to environmental issues. The publications reflect these practices through case studies as well as provide results of environmental management system research. When dealing with sustainability issues in the military, management is used as a support methodology and not as a separate discipline.

To conclude, social sustainability is currently the dominant topic in the field of sustainability in the military. Nevertheless, the situation is changing as the topic of environmental sustainability is getting more and more attention. Environmental sustainability in the military integrates multidisciplinary approach and the isolation between research on environmental, economic and social sustainability is disappearing. We can predict that in the nearest future a comprehensive body of knowledge on sustainability in the military is going to be formed.

\section{References}

Ahronson A, Cameron JE (2007) The nature and consequences of group cohesion in a military sample. Military Psychology 19:9-25

Anglani N, Oriti G, Colombini M (2017) Optimized Energy Management System to Reduce Fuel Consumption in Remote Military Microgrids. IEEE Trans. on Ind. Applicat. 53:5777-5785. https://doi.org/10.1109/TIA.2017.2734045

Banks SB, Stytz MR (2003) Progress and Prospects for the Development of Computer-Generated Actors for Military Simulation: Part 2-Reasoning System Architectures and Human Behavior Modeling. Presence: Teleoperators and Virtual Environments 12:422-436. https://doi.org/10.1162/105474603322391640

Bedwell WL, Wildman JL, DiazGranados D, Salazar M, Kramer WS, Salas E (2012) Collaboration at work: An integrative multilevel conceptualization. Human Resource Management Review 22:128-145. https://doi.org/10.1016/j.hrmr.2011.11.007

Bildirici M (2018) Impact of militarization and economic growth on biofuels consumption and CO 2 emissions: The evidence from Brazil, China, and US. Environ. Prog. Sustainable Energy 37:1121-1131. https://doi.org/10.1002/ep.12720

Brailey K, Vasterling JJ, Proctor SP, Constans J, Friedman MJ (2007) PTSD symptoms, life events, and unit cohesion in U.S. soldiers: Base- 
line findings from the neurocognition deployment health study. Journal of Traumatic Stress 20:495-503. https://doi.org/10.1002/jts.20234 Budgen D, Brereton P (2006) Performing systematic literature reviews in software engineering. Available on the Internet: http://dl.acm. org/ft_gateway.cfm?id=1134500\&type=pdf

Charbonneau D, Wood VM (2018) Antecedents and outcomes of unit cohesion and affective commitment to the Army. Military Psychology 30:43-53. https://doi.org/10.1080/08995605.2017.1420974

CRExplorer: Cited References Explorer. Software. Thor A. University of Applied Sciences for Telecommunications Leipzig (HfTL)

Dunlap A (2016) Counterinsurgency for wind energy: The Bíi Hioxo wind park in Juchitán, Mexico. The Journal of Peasant Studies 45:630-652. https://doi.org/10.1080/03066150.2016.1259221

Fayiga AO, Saha U (2016) The effect of bullet removal and vegetation on mobility of $\mathrm{Pb}$ in shooting range soils. Chemosphere 160 : 252-257. https://doi.org/10.1016/j.chemosphere.2016.06.098

Green defence Framework (2014) NATO Defence Policy and Planning Committee

Greenburg J (2017) Selling Stabilization: Anxious Practices of Militarized Development Contracting. Development and Change 48:1262-1286. https://doi.org/10.1111/dech.12348

Griffith J (2002) Multilevel analysis of cohesion's relation to stress, well-being, identification, disintegration, and perceived combat readiness. Military Psychology 14:217-239

Hardcastle LR, Perry M, Browne A (2015) Preventive medicine oversight of splash pads on military installations. US Army Med Dep J:32-37

Havlíček M, Skokanová H, Dostál I, Vymazalová M, Pavelková R, Petrovič F (2018) The consequences of establishing military training areas for land use development-A case study of Libavá, Czech Republic. Land Use Policy 73:84-94. https://doi.org/10.1016/j. landusepol.2018.01.039

HistCite Software LLC, 2004-2009

Hoskin K(2004) Spacing, timing and the invention of management. Organization 11:743-757. https://doi.org/10.1177/1350508404047249

Hubbard EE, Villadsen A, Rathje P, Jensen CC, Haselbach M, Sakintuna B (2017) Planning Green in Cities and Military Installations. In: Goodsite M (ed) Green defense technology: Triple net zero energy, water and waste models and applications. Springer Berlin Heidelberg, New York NY, pp 253-268

IEEE Thesaurus Version 1.0 (2017): The Institute of Electrical and Electronics Engineers (IEEE). Available on the Internet: https:// www.ieee.org/content/dam/ieee-org/ieee/web/org/pubs/ieee_thesaurus.pdf

JEL Classification System (2016) 54:760-775. https://doi.org/10.1257/jel.54.2.760

Jorgenson AK, Clark B (2009) The Economy, Military, and Ecologically Unequal Exchange Relationships in Comparative Perspective: A Panel Study of the Ecological Footprints of Nations, 1975-2000. Social Problems 56:621-646. https://doi.org/10.1525/ sp.2009.56.4.621

Jorgenson AK, Clark B (2016) The temporal stability and developmental differences in the environmental impacts of militarism: The treadmill of destruction and consumption-based carbon emissions. Sustain Sci 11:505-514. https://doi.org/10.1007/s11625-015-0309-5

Jugnia LB, Manno D, Drouin K, Hendry M (2018) In situ pilot test for bioremediation of energetic compound-contaminated soil at a former military demolition range site. Environ Sci Pollut Res Int 25:19436-19445. https://doi.org/10.1007/s11356-018-2115-y

Kaikkonen NM, Laukkala T (2016) International military operations and mental health--A review. Nord J Psychiatry 70:10-15. https:// doi.org/10.3109/08039488.2015.1048718

Kentor J, Jorgenson A (2017) Military expenditures and health: A cross-national study, 1975-2000. Int J of Soc \& Social Policy 37: 755-772. https://doi.org/10.1108/IJSSP-01-2017-0004

Kentor J, Jorgenson AK, Kick E (2012) The "new” military and income inequality: A cross national analysis. Soc Sci Res 41:514-526. https://doi.org/10.1016/j.ssresearch.2011.12.005

Kim CJ (2017) Bases That Leave: Consequences of US Base Closures and Realignments in South Korea. Journal of Contemporary Asia 48:339-357. https://doi.org/10.1080/00472336.2017.1397728

Kirton JJ, Maclaren VW (2018) Linking Trade, Environment, and Social Cohesion: NAFTA Experiences, Global Challenges. Available on 
the Internet: https://content.taylorfrancis.com/books/download?dac=C2017-0-57114-6\&isbn=9781351745369\&format=googlePreviewPdf Lee J (2016) The Regional Economic Effects of Military Base Realignments and Closures. Defence and Peace Economics 29:294-311. https://doi.org/10.1080/10242694.2016.1170335

MacCoun RJ, Kier E, Belkin A (2006) Does social cohesion determine motivation in combat? An old question with an old answer. Armed Forces \& Society 32:646-654

Marzec RP (2015) Militarizing the environment: Climate change and the security state / Robert P. Marzec. University of Minnesota Press, Minneapolis, London

McLauchlin T (2014) Desertion, terrain, and control of the home front in civil wars. Journal of Conflict Resolution 58:1419-1444

McLauchlin T (2015) Desertion and collective action in civil wars. International Studies Quarterly 59:669-679

Mitchell MM, Gallaway MS, Millikan AM, Bell M (2012) Interaction of combat exposure and unit cohesion in predicting suicide related ideation among post deployment soldiers. Suicide and Life Threatening Behavior 42:486-494

Oglanis, A., Loizidou M. (2017) Study of environmental management systems on defence. Global Journal of Environmental Science and Management 3.1:103-120. https://doi.org/0.22034/GJESM.2017.03.01.010

Oliver LW, Harman J, Hoover E, Hayes SM, Pandhi NA (1999) A quantitative integration of the military cohesion literature. Military Psychology 11:57-83

Pidlisnyuk V, Trögl J, Stefanovska T, Shapoval P, Erickson L (2016) Preliminary Results on Growing Second Generation Biofuel Crop Miscanthus X Giganteus at The Polluted Military Site in Ukraine. Nova Biotechnologica et Chimica 15:54. https://doi.org/10.1515/ nbec-2016-0008

Procter AC, Kaplan PÖ, Araujo R (2016) Net Zero Fort Carson: Integrating Energy, Water, and Waste Strategies to Lower the Environmental Impact of a Military Base. Journal of Industrial Ecology 20:1134-1147. https://doi.org/10.1111/jiec.12359

Rao NH (2005) Environmental management: Relevance and implications for management of defence installations for sustainability. Current Science 88:1753-1758

Ritz A, Brewer GA, Neumann O (2016) Public Service Motivation: A Systematic Literature Review and Outlook. Public Admin Rev 76:414-426. https://doi.org/10.1111/puar.12505

Sabatini JJ, Nagori AV, Chen G, Chu P, Damavarapu R, Klapötke TM (2012a) High Nitrogen Based Pyrotechnics: Longer and Brighter Burning, Perchlorate Free, Red Light Illuminants for Military and Civilian Applications. Chemistry-A European Journal 18:628-631

Sabatini JJ, Raab JM, Hann Jr RK, Damavarapu R, Klapötke TM (2012b) High Nitrogen Based Pyrotechnics: Development of Perchlorate Free Green Light Illuminants for Military and Civilian Applications. Chemistry-An Asian Journal 7:1657-1663

Siebold GL (2007) The essence of military group cohesion. Armed Forces \& Society 33:286-295

Smaliukienė R, Bekešienė S, Piotrowska-Trybull M (2011) Sustainability Issues in the Military: Application of Computer-Supported Collaborative Learning. JSSI 1:123-131. https://doi.org/10.9770/jssi.2011.1.2(5)

Tang J H, Lai C C, Lin ES (2009) Military Expenditure and Unemployment Rates: Granger Causality Tests Using Global Panel Data. Defence and Peace Economics 20:253-267. https://doi.org/10.1080/10242690903105257

Tvaronavičienė, M., Mentel, G., \& Chyrva, H. (2018) Leadership in Energy Security: Behavioral Patterns and Long-Term Energy Intensity. In Leadership for the Future Sustainable Development of Business and Education (pp. 591-601). Springer, Cham. https://doi. org/10.1007/978-3-319-74216-8_59

VosViewer (2018). Centre for Science and Technology Studies, Leiden University, The Netherlands

Wang XJ, Ji YZ, Li XJ, Wang S (2013) Experimental Research on Adsorption Treatment of Military Agent Contaminated Water Using Activated Carbon. AMR 800:614-619. https://doi.org/10.4028/www.scientific.net/AMR.800.614

Webster J, Watson RT (2002) Analyzing the past to prepare for the future: Writing a literature review. MIS quarterly 26 (2): xiii-xxiii. Available on the Internet: https://www.jstor.org/stable/4132319

Wu W, Wang X, Paull D, Kesby J (2010) Defence force activities in marine protected areas: Environmental management of Shoalwater Bay Training Area, Queensland, Australia. Chinese Journal of Oceanology and Limnology 28:667-676. https://doi.org/10.1007/s00343010-9113-3 